\title{
Short term histopathological effects of GaAlAs laser on experimentally induced TMJ osteoarthritis in rabbits
}

\section{Sadi MEMIS(a) \\ Celal CANDIRLI(b) \\ Gokcen KERIMOGLU(c)}

(a)Abant lzzet Baysal University, Faculty of Dentistry, Department of Oral and Maxillofacial Surgery, Bolu, Turkey.

(b)Karadeniz Technical University, Faculty of Dentistry, Department of Oral and Maxillofacial Surgery, Trabzon, Turkey.

(c) Karadeniz Technical University, Faculty of Medicine, Department of Histology and Embryology, Trabzon, Turkey.
Declaration of Interests: The authors certify that they have no commercial or associative interest that represents a conflict of interest in connection with the manuscript.

\begin{abstract}
The aim of this study was to evaluate the biostimulation (BS) effect of the gallium-aluminum-arsenide (GaAlAs) diode laser by histopathology with an experimental osteoarthritis (OA) model in the temporomandibular joints (TMJ) of rabbits, in the early period. GaAlAs diode laser is used for pain reduction in TMJ disorders. Twenty-four adult male New Zealand white rabbits were randomly divided into three equal groups: Control Group (CG), Study Group 1 (SG-1), and Study Group 2 (SG-2). Mono-iodoacetate (MIA) was administered to the right TMJs of all rabbits. The rabbits did not undergo any treatment for four weeks to allow the development of osteoarthritis. In SG-1, laser BS was applied to the rabbits at $940 \mathrm{~nm}, 5 \mathrm{~W}$, and $15 \mathrm{~J} / \mathrm{cm}^{2}$ in continuous wave mode at 48 hour intervals for 14 sessions; and in SG-2, laser BS was applied with the same parameters at 24-hour intervals for 28 sessions. Laser BS was not applied to the rabbits in CG. All rabbits were sacrificed simultaneously. The TMJ cartilage, osteochondral junction, chondrocyte appearance, and subchondral ossification were evaluated histopathologically. There was no statistically significant difference between the groups in terms of cartilage, osteochondral junction, chondrocyte appearance, and subchondral ossification values $(p>0.05)$. The laser BS protocol used in the study had no positive histopathological effects on TMJ OA in the early period.
\end{abstract}

Keywords: Arthritis, Experimental; Lasers, Semiconductor; Temporomandibular Joint.

\section{Introduction}

\section{Corresponding Author:}

Sadi Memis

E-mail: sadimemis@gmail.com;

sadimemis@windowslive.com

https://doi.org/10.1590/1807-3107bor-2018.vol32.0090

Submitted: January 01, 2018

Accepted for publication: June 06, 2018

Last revision: July 18, 2018
Osteoarthritis $(\mathrm{OA})$ is a chronic degenerative disease that is characterized by cartilage destruction, osteophyte formation, and subchondral sclerosis, and occurs in a progressive manner specific to synovial, diarthrodial, and load-bearing joints. The disease manifests as slow and progressive, and can be monoarticular or polyarticular., ${ }^{1,2}$ Temporomandibular joint (TMJ) OA is a disease characterized by severe cartilage degradation, subchondral bone remodeling, synovitis, and chronic pain., ${ }^{3,45}$ Although it is known to be based on inflammation and subchondral bone remodeling, the pathogenesis of TMJ OA is not clear. ${ }^{4}$ This issue is controversial due to the long-term disease course, in general. However, it is thought to develop due to an increased load on the joints ${ }^{6}$ of which continuation causes deterioration in the articular surface and subarticular structures. ${ }^{7}$ 
Prevalence determination of TMJ OA is difficult because there is no relationship between the clinical manifestations and the structural changes occurring in the articular cartilage. Although histological features are estimated to be present in 40 to $60 \%$ in the community ${ }^{8}$, clinical symptoms are seen in $8-16 \%$ of patients. ${ }^{9}$ Moreover, $44 \%$ of asymptomatic patients have radiographic signs of TMJ OA. ${ }^{9}$

Various procedures ranging from conservative treatment to surgical treatment are applied to patients with TMJ OA. Conservative procedures include recommendations to avoid forced movements of the mandible, prescription of analgesic and antiinflammatory drugs, splint therapy, thermal therapy, or minimally invasive methods. ${ }^{10,11}$ Radical treatment procedures ranging from open joint surgery (arthroplasty) to TMJ replacement can be performed in patients in whom medications and conservative treatment options have failed. ${ }^{10}$ However, since radical treatments are associated with the risk of intraoperative and postoperative complications, it is necessary to develop alternative conservative treatment modalities.

Gallium aluminum arsenide (GaAlAs) lasers are members of the semiconductor laser family, which typically uses a combination of gallium crystals, aluminum, and arsenide to transform electrical energy into light energy. ${ }^{12} \mathrm{GaAlAs}$ diode lasers are generally set at between $800-980 \mathrm{~nm}$ wavelength for therapeutic usage, which fall into the near infrared area (also called "infrared $A$ ") in the electromagnetic spectrum. ${ }^{13}$ Since this type of laser beam at the $940 \mathrm{~nm}$ wavelength is not perceived by the naked eye due to the area falling on the electromagnetic spectrum, it is applied with the deep tissue handpiece proposed for TMD and TMJ conditions, which contains a special red light showing the application area. The biostimulation effects of GaAlAs lasers have been demonstrated in clinical and animal studies before. Cellular and clinical studies have shown that GaAlAs lasers enhance the activation of fibroblasts and osteoblasts, aid the healing of soft tissues, and increase alveolar bone remodeling rate through the light energy from the laser beam being converted to chemical energy in the cell. ${ }^{14,15}$ However, in the TMJ region at the level of cellular response, the histopathological effects of GaAlAs lasers are not known precisely.
GaAlAs diode lasers are the most preferred lasers by doctors and dentists for pain treatment of muscles, tendons, and joints. ${ }^{13}$ Today, although laser BS is the preferred option for reducing pain in various TMJ disorders, ${ }^{16,17}$ it is not well known whether, or to what extent, laser BS creates histopathological changes in the TMJ. There is also no definitive BS treatment protocol for patients with TMJ OA.

In this study, the purpose was to evaluate the BS effect of the GaAlAs diode laser on experimental OA in the TMJs of rabbits, in the early stage, by histopathological exam.

\section{Methodology}

This study was approved by the Animal Experimentation Ethics Committee of Karadeniz Technical University (Process number: 2014/17). Twenty-four adult male New Zealand white rabbits (weight: $2.5-3.0 \mathrm{~kg}$ ) were used in the study. The rabbits were housed on a 12-hour light:12-hour dark cycle at $21^{\circ} \mathrm{C}$ in partitioned cages in a clean, warm, artificially illuminated, and sunny environment. The rabbits were randomly divided into three equal groups; Control Group (CG), Study Group 1 (SG-1), and Study Group 2 (SG-2). Intraarticular mono-iodoacetate (MIA) injections were performed into the right TMJs of all rabbits to create the experimental OA. The CG did not receive treatment. For the treated groups, two different laser BS protocols were planned as described in the "Laser Biostimulation Protocol" section. Rabbits in SG-1 received 14 sessions and rabbits in SG-2 received 28 sessions of laser BS.

\section{Formation of the Experimental OA}

Ketamine hydrochloride $\left(50 \mathrm{mg} / \mathrm{kg}\right.$, Ketalar ${ }^{\circledR} \mathrm{flk}$., Pfizer, $50 \mathrm{mg} / \mathrm{mL}$ solution) and $5 \mathrm{mg} / \mathrm{kg}$ xylazine hydrochloride (Rompun ${ }^{\circledR}$ enj $2 \%$ sol., Bayer, Germany) were administered intramuscularly to the rabbits in order to provide anesthesia. Afterwards, the skin of the TMJ was exposed, and antisepsis was achieved using $10 \%$ povidone-iodine solution (Betadine ${ }^{\circledR}$ sol., Kansuk, Turkey). As reported by Guler et al., ${ }^{18}$ in order to develop experimental OA, MIA (Sigma I 2512-25G, St. Louis, MO, USA) was prepared as $3 \mathrm{mg} / \mathrm{mL}$ solution in an amount sufficient for the TMJs of 24 rabbits. 
Fifty microliters of the MIA solution was injected intraarticularly into the right TMJs of all rabbits in CG, SG-1, and SG-2 (Figure 1A). A period of 4 weeks was allowed for the induction of OA signs in the tissues.

\section{Laser biostimulation protocol}

Following the waiting period after the injection of MIA, for SG-1 and SG-2, the laser probe was placed perpendicularly to the cutaneous surface on the right TMJ. The GaAlAs diode laser (Ezlase 940 diode laser, Biolase, USA) was applied to the rabbits at $940 \mathrm{~nm}, 5$ $\mathrm{W}$ and $15 \mathrm{~J} / \mathrm{cm}^{2}$ in continuous wave mode. For SG-1, applications were done at 48-hour intervals for 14 sessions (Figure 1B) and for SG-2, applications were done at 24-hour intervals for 28 sessions. No treatment was applied to the left TMJ of the rabbits. Laser BS was not applied to the TMJ of the rabbits in the control group, which were kept in the cages to be simultaneously sacrificed with the rabbits in SG-1 and SG-2.

\section{Histological procedures}

At the end of BS, an overdose of thiopental sodium (100 mg/kg) (Ekipental, Tum-Ekip Pharmaceuticals Inc., Istanbul) was intracardially administered to the rabbits for euthanasia.

The joints were cut under irrigation and excised en bloc with $2 \times 1 \mathrm{~cm}$ in size (Figure $1 \mathrm{C}$ ). TMJs were fixed in $10 \%$ formaldehyde solution for 48 hours and then placed in a decalcifying solution containing $10 \%$ formic acid. The solution was changed every two days during the decalcification process. ${ }^{19}$ All joints were decalcified for 25 days in average. The joints were washed in water and then dehydrated through a series of ethyl alcohol solutions. After, the joints were treated with xylene to become transparent and embedded in paraffin.

Five-micrometer-thick sections were obtained from the joints embedded in paraffin using a microtome (Leica RM2255, Germany). They were hydrated by alcohol/xylene series after being removed from paraffin. All sections were stained with hematoxylin and eosin (H\&E) staining protocol. Sections were passed through a graded series of ethanol and xylene and then covered with a coverslip.

The slides were examined under a light microscopy (Olympus BX-51; Olympus Co., Tokyo, Japan) and photographed by a camera (Olympus DP 71
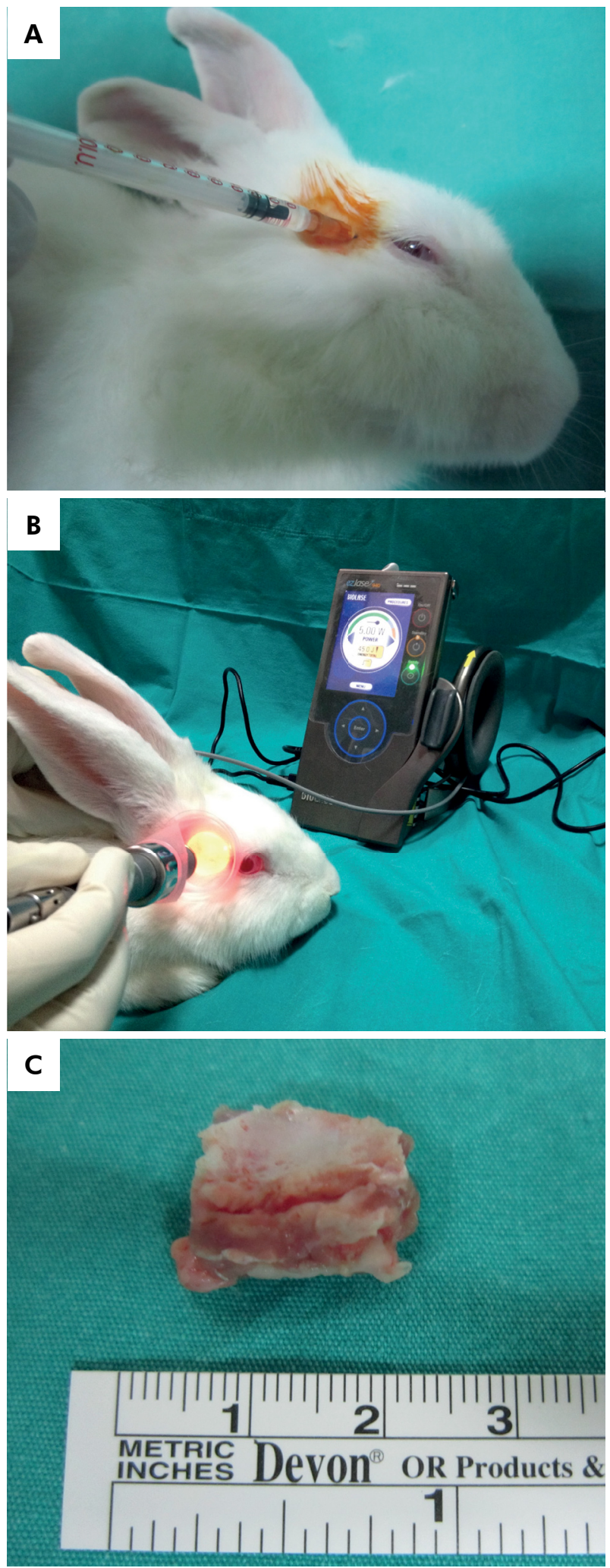

Figure 1. A. Injection of MIA solution into the right TMJ in the study groups. B. Application of the GaAlAs diode laser to SG-1 and SG-2. C. En bloc excision of the TMJ. 
Olympus Co., Japan). The slides prepared for each TMJ were evaluated in terms of articular cartilage, osteochondral junction, chondrocyte appearance, and histologic changes in subchondral bone structure. The following classifications were used for the evaluation: articular cartilage $=$ normal, thickened, and thinned; chondrocyte appearance $=$ normal, hypocellular, and clustered; osteochondral junction = normal, invaginated, and weak; and subchondral bone structure $=$ normal and increased trabecular bone. ${ }^{18,20}$ In addition, the joints that showed normal histological structure in terms of articular cartilage, chondrocyte appearance, and osteochondral junction were classified as "Normal" and the joints that exhibited signs of osteoarthritis or pathological changes were classified as "Abnormal".

\section{Statistical analysis}

The IBM SPSS 22 Statistical Software (IBM Corporation Armonk, NY, USA) was used to analyze the data. The Chi-square and binomial tests were performed to examine the homogeneity of the categorical data. For data comparison, the Pearson's Chi-square test, the linear-by-linear association test, and the Fisher's exact tests were used together with the Monte Carlo simulation technique. The categorical data are reported as $\mathrm{n}$ (number) and percentage (\%). A 95\% confidence level was used and a p-value less than 0.05 was considered statistically significant.

\section{RESULTS}

Unfortunately, one rabbit from SG-1 and two rabbits from SG-2 were lost due to their inability to adapt to stress and environment during the study period. All the other animals completed the study without complications, and the final distribution of the rabbits in the groups was as follows: $\mathrm{CG}(\mathrm{n}=8)$, SG-1 $(n=7)$, and SG-2 $(n=6)$.

Histopathological findings of $\mathrm{OA}$ were seen in all TMJs except for one joint in SG-1. Various histological sections (articular cartilage, osteochondral junction, chondrocyte appearance, and subchondral bone) from the TMJ samples are shown in Figure 2.

Table. Results of articular cartilage, osteochondral junction, chondrocyte appearance, and subchondral bone according to the groups.

\begin{tabular}{|c|c|c|c|c|c|}
\hline \multirow{2}{*}{ Variable } & Control group & Study Groupl (14 s. laser) & Study Group2 (28 s. laser) & Total & \multirow{2}{*}{$p$-value } \\
\hline & $\mathrm{n}=8$ & $\mathrm{n}=7$ & $n=6$ & $\mathrm{n}=21$ & \\
\hline \multicolumn{6}{|l|}{ Articular cartilage } \\
\hline Thinned & $4(\% 50)$ & $2(\% 28.6)$ & $0(\% 0)$ & $6(\% 28.6)$ & \multirow{3}{*}{$0.203^{*}$} \\
\hline Normal & $1(\% 12.5)$ & $2(\% 28.6)$ & $3(\% 50)$ & $6(\% 28.6)$ & \\
\hline Thickened & $3(\% 37.5)$ & $3(\% 42.9)$ & $3(\% 50)$ & 9 (\%42.8) & \\
\hline Normal & $1(\% 12.5)$ & $2(\% 28.6)$ & $3(\% 50)$ & $6(\% 28.6)$ & \multirow{2}{*}{$0.349^{* * *}$} \\
\hline Abnormal & $7(\% 87.5)$ & $5(\% 71.4)$ & $3(\% 50)$ & $15(\% 71.4)$ & \\
\hline \multicolumn{6}{|l|}{ Osteochondral junction } \\
\hline Normal & $0(\% 0)$ & $3(\% 42.9)$ & $2(\% 33.3)$ & $5(\% 23.8)$ & \multirow{3}{*}{$0.107^{* *}$} \\
\hline Invaginated & $4(\% 50)$ & $3(\% 42.9)$ & $4(\% 66.7)$ & $11(\% 52.4)$ & \\
\hline Weak & $4(\% 50)$ & $1(\% 14.3)$ & $0(\% 0)$ & 5 (\%23.8) & \\
\hline Normal & $0(\% 0)$ & $3(\% 42.9)$ & 2 (\%33.3) & $5(\% 23.8)$ & \multirow{2}{*}{$0.135^{* * *}$} \\
\hline Abnormal & $8(\% 100)$ & $4(\% 57.1)$ & $4(\% 66.7)$ & $16(\% 76.2)$ & \\
\hline \multicolumn{6}{|l|}{ Chondrocyte appearance } \\
\hline Clustered & $4(\% 50)$ & 1 (\%14.3) & 2 (\%33.3) & 7 (\%33.3) & \multirow{3}{*}{$0.687^{* *}$} \\
\hline Normal & $2(\% 25)$ & $4(\% 57.1)$ & $3(\% 50)$ & $9(\% 42.9)$ & \\
\hline Hypocellular & $2(\% 25)$ & $2(\% 28.6)$ & $1(\% 16.7)$ & $5(\% 23.8)$ & \\
\hline Normal & $2(\% 25)$ & $4(\% 57.1)$ & $3(\% 50)$ & $9(\% 42.9)$ & \multirow{2}{*}{$0.551^{* * *}$} \\
\hline Abnormal & $6(\% 75)$ & $3(\% 42.9)$ & $3(\% 50)$ & $12(\% 57.1)$ & \\
\hline \multicolumn{6}{|l|}{ Subchondral } \\
\hline Normal & $3(\% 37.5)$ & $3(\% 42.9)$ & $4(\% 66.7)$ & $10(\% 47.6)$ & \multirow{3}{*}{$0.641^{* * *}$} \\
\hline Bone structure & & & & & \\
\hline Increased trabecularl bone & $5(\% 62.5)$ & $4(\% 57.1)$ & 2 (\%33.3) & $11(\% 52.4)$ & \\
\hline
\end{tabular}



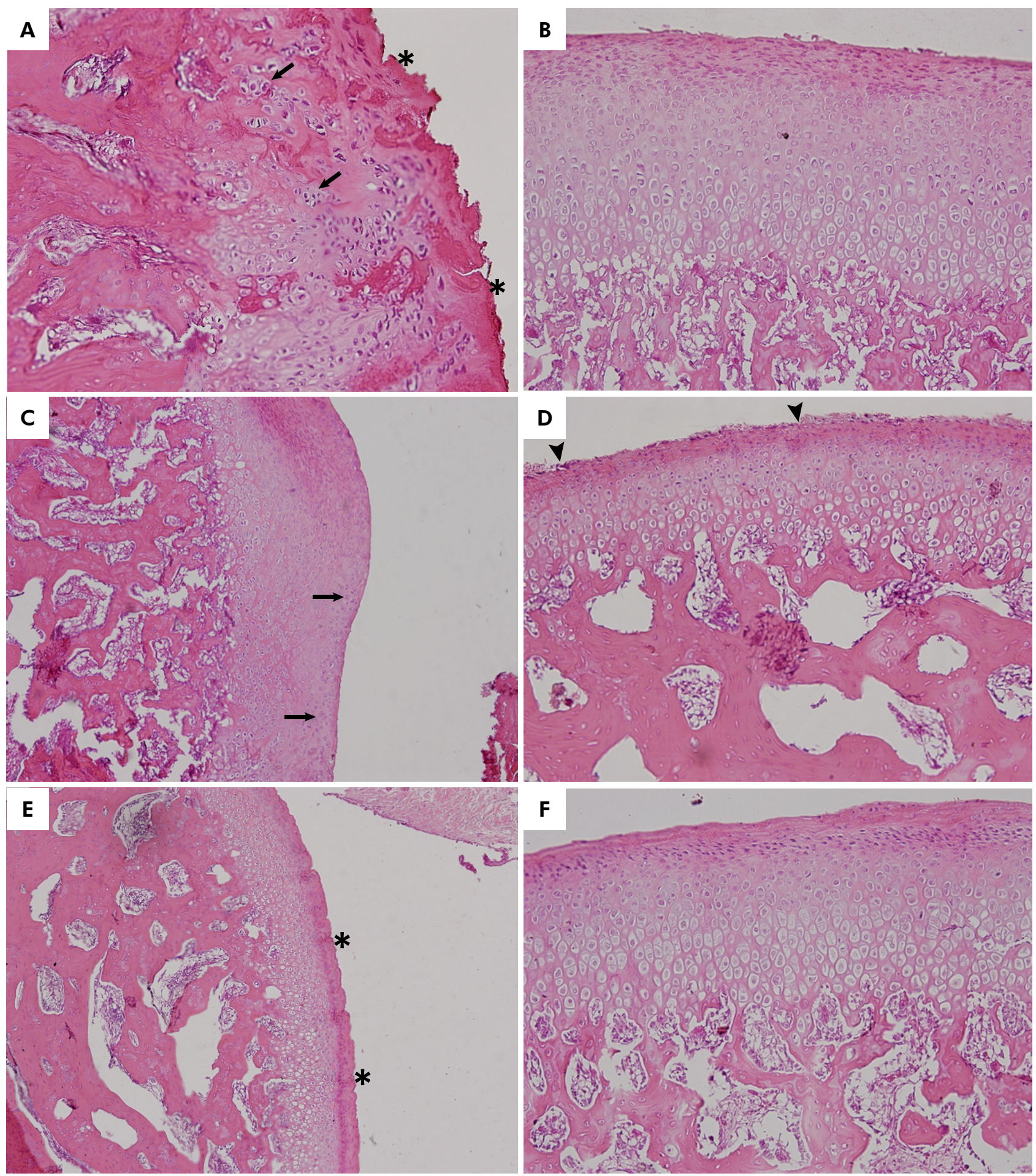

Figure 2. Appearance of TMJ sections of the groups under light microscope with Hematoxylin \& Eosin staining. A. In CG, surface irregularities and fissures $\left({ }^{*}\right)$ are seen in articular cartilage. Chondrocyte clusters and increased subchondral trabecular bone density $(\uparrow)$ are seen. B. In CG, articular cartilage is thickened. C. In CG, articular cartilage is thickened and chondrocyte clusters $(\uparrow)$ are present. D. In SG-1, cartilage thinning and fibrillation $(\mathbf{\Lambda})$ as well as increased subchondral trabecular bone density are seen. E. In SG-1, surface irregularities $\left({ }^{*}\right)$ and thinning are seen in articular cartilage and increased subchondral trabecular bone density are present (H \& E, 100X). F. In SG-2, normal chondrocytes, cartilage thickening, and osteochondral invagination are seen (H \& E, 200X). 
The changes in articular cartilage, osteochondral junction, chondrocyte appearance, and subchondral bone were recorded as number and percentage and are shown in Table.

There was no statistically significant difference between the groups in terms of articular cartilage $(p=0.203)$. The samples that showed decreased or increased articular cartilage thickness (OA findings) were combined under the "Abnormal" category. According to this new classification, there was no statistically significant difference between the two "Normal" and "Abnormal" groups $(\mathrm{p}=0.349)$.

No significant difference between the groups was found in terms of osteochondral junction $(p=0.107)$. The samples that showed invaginated or weak osteochondral junction (OA findings) were combined under the "Abnormal" category. According to this new classification, there was still no difference between the "Normal" and "Abnormal" groups $(\mathrm{p}=0.135)$.

There was no significant difference between the groups in terms of chondrocyte appearance $(p=0.687)$. The samples that showed clustering or hypocellularity (OA findings) were combined under the "Abnormal" category, without significant difference between the "Normal" and "Abnormal" groups ( $p=0.551$ ).

No significant difference was found between the groups in terms of subchondral bone $(p=0.641)$.

\section{Discussion}

$\mathrm{OA}$, which is one of the TMJ disorders, can be briefly described as a disease characterized by severe cartilage degradation, subchondral bone remodeling, synovitis, and chronic pain. ${ }^{3,4}$ Since the level of inflammatory mediators in TMJ OA is low, there are different opinions on whether or not it is an inflammatory disease. Although its etiology is unclear, several researchers think that severe malocclusion, mandibular skeletal asymmetry, and muscle overwork are the predisposing factors for TMJ OA. ${ }^{4,82,22}$ Although inflammation of the mandibular condylar cartilage and subchondral bone remodeling are responsible for TMJ OA, the pathogenesis of TMJ $\mathrm{OA}$ is unclear, and this issue is controversial. ${ }^{4}$

Experimental osteoarthritis models with similar mechanism as in humans are used to study the pathogenesis of TMJ OA., ${ }^{9,23}$ MIA $^{24,25}$, interleukin-1, and tumor necrosis factor- $\alpha,{ }^{26}$ which are administered intraarticularly and target the articular cartilage cells, are used to create the models. MIA, which is frequently used for TMJ disorders in the literature, was used in our study; it acts by inhibiting the glycolytic metabolism of chondrocytes, ${ }^{24,25,27}$ resulting in cell death and eventually OA.

Since cartilaginous changes in the early stages of $O A$ cannot be detected radiographically and degenerative changes can be observed in late stages, it is difficult to establish a relationship between clinical and radiological findings. ${ }^{28,29,30}$ For this reason, we planned a histopathological study to evaluate early results.

Methods used in the treatment of TMJ OA have been defined by Mercuri ${ }^{31}$ as non-invasive, minimally invasive, invasive surgical, and rescue procedures. It seems that the GaAlAs laser BS has not been used as a treatment step.

Conventional treatments for TMJ OA are mainly aimed at eliminating pain, improving function, and modifying cartilage damage. To reduce the symptoms of TMJ OA, NSAIDs and muscle relaxants are prescribed. Long-term treatment can be a disadvantage for patients. Patient motivation must be high and continuous for the use of oral appliances, which are one of the non-invasive methods; however, oral appliances do not give a definitely positive result. Although physical therapy helps reduce pain, heavy exercises can reduce the quality of life of patients. Intraarticular corticosteroid injections are minimally invasive OA treatments but are rarely used and it is known that repeated injections can increase the risk of infection or cartilage destruction. ${ }^{31}$ The therapeutic efficacy of arthrocentesis, which is frequently used for the treatment of TMJ OA, remains controversial. ${ }^{32}$ Due to the risk of complications associated with invasive surgical techniques such as arthroplasty and osteotomy, it is necessary to develop a new treatment method for TMJ OA. We have been focusing on the question whether the GaAlAs laser BS, which is increasingly used in orthopedics and dentistry, can be a noninvasive treatment protocol for TMJ OA.

New Zealand white rabbits were used in our study. This breed of rabbit has the appropriate tissue, size, and anatomy to perform this study, and provides a 
suitable physiological model for mimicking TMJ OA in humans. In accordance with similar studies, male rabbits were used to avoid hormonal effects on bone and articular cartilage. ${ }^{18,20}$

In our study, articular cartilages, osteochondral junctions, chondrocytes, and subchondral bone tissues were evaluated to investigate OA findings. Moreover, articular cartilage thinning or thickening, invaginated or weak osteochondral junction, chondrocyte clusters or hypocellularity, and increased subchondral trabecular bone density were evaluated. $18,24,25,33$

The GaAlAs diode laser, which is commonly applied for pain treatment of muscles, tendons, and joints, was used in our study. For biostimulation, the effective penetration depth of the laser is $2-3 \mathrm{~cm} \cdot{ }^{26}$ As the left TMJs of the rabbits in SG-1 and SG-2 could be affected primarily or secondarily by laser BS applied in the contralateral side, only the right TMJs of the rabbits were evaluated in the study groups to guarantee the reliability of the study.

The positive effect on connective tissue healing reported by Ng et al..$^{27}$ was used to plan the protocols for multiple sessions of laser BS. Moreover, the laser was applied transcutaneously to the TMJ of rabbits in SG-1 for 14 sessions and in SG-2 for 28 sessions. As suggested by Park et al., ${ }^{14}$ 24-hour and 48-hour intervals was allowed between sessions for SG-2 and SG-1, respectively. While a total of $630 \mathrm{~J}$ was given for each joint in the 14 sessions of SG-1, a total of $1260 \mathrm{~J}$ was given for each joint in 28 sessions of SG-2.

Some authors recommend that laser BS should be applied at high parameters in order to affect hard tissue healing. ${ }^{34,35}$ However, some other authors advocate the exact opposite. ${ }^{36,37}$ The energy density is the most important parameter in laser BS. In in vitro studies on rabbits by Jia and Guo, ${ }^{38}$ the BS effect was greater in articular chondrocytes of groups treated with a high energy density than in control groups. Moore et al. ${ }^{39}$ supported that the energy density can be increased up to $24 \mathrm{~J} / \mathrm{cm}^{2}$ in laser BS. An energy density within the recommended limits by Fikackova et al. ${ }^{40}$ for TMJ disorders was selected in our study $\left(15 \mathrm{~J} / \mathrm{cm}^{2}\right)$.

Our results showed that there was more normal tissue in the articular cartilages treated with laser BS compared to control. However, the differences were not statistically significant. When considering the rates of thickening and thinning (an early sign of OA) especially in the fibrous layer of articular cartilage, it was seen that the positive histopathological effect of laser BS on articular cartilage was not sufficient. As reported by Alves et al., ${ }^{41}$ this result can be attributed to the fact that laser BS primarily undertakes the task to modulate the inflammatory process in OA by stimulating anti-inflammatory mediators. ${ }^{41}$ Although the mechanisms of BS are not fully known, the time required for cell regeneration may differ from the time needed to change the amount of the released mediator. Positive results were obtained in studies of $\mathrm{OA}$, in which pain, comfort, and function were evaluated using laser BS in the literature, however this may be the reason why histopathological changes could not be demonstrated.

Despite that normal osteochondral junction had a higher percentage in the study groups treated with laser BS, there was no significant difference between the groups. Kamali et al..$^{42}$ investigated the therapeutic effect of laser on cartilage defects in the rabbit knee joint and observed an increase in stiffness and firmness at the osteochondral junctions at eight weeks. In our study, the lack of positive results in the treated osteochondral junctions can be attributed to early evaluation.

When the number of normal tissue samples was compared with that of samples with OA finding (the presence of clustering or hypocellularity in chondrocytes), there was no difference between the groups. Chondrocyte clusters are seen in the early stage of OA, which provide evidence that OA occurred in our study. ${ }^{33,43}$ Hypocellularity is a more common finding in the late stage of $\mathrm{OA}$, and occurs due to apoptotic cell death. ${ }^{33,43}$ In our study, although chondrocyte clustering was not statistically significant, it was found to be higher as a percentage in the control group than in the treated groups. This result can be attributed to the regeneration ability of laser BS on chondrocytes. ${ }^{42}$ Our study also supported the finding by Torricelli et al. ${ }^{44}$ that no cellular damage in the chondrocytes is caused by the GaAlAs laser BS.

It is known that OA can cause pathological changes in the subchondral bone. Therefore, subchondral bone tissue showing an increase in trabecular bone, 
which is a finding of $\mathrm{OA}$ and a defense response of tissues, was most often seen in the CG samples (62.5\%). Although the percentage of normal subchondral bone tissue was higher in the study groups treated with laser BS, the differences between the groups were not statistically significant. The increase of normal subchondral bone tissue can be linked to the ability of laser BS to increase tissue regeneration. ${ }^{45}$ Subchondral bone sclerosis or subchondral cysts, which are seen in the late phase of OA, were not observed. The increased trabecular bone density, which was considered an early sign of OA in our study, was consistent with findings of the MIA study on rabbits by Duygu et al. ${ }^{18}$

When new methods are sought for treatment of a joint disease that clinically manifests as persistent pain (such as OA), the amount of pain relief must be considered. The absence of histopathological changes in tissues after laser BS does not imply that clinical symptoms of OA cannot be reduced; a positive effect

\section{References}

1. Di Cesare PE. Kelley's Textbook of Rheumatology: Pathogenesis of osteoarthritis. Philadelphia (Pa): Elsevier Saunders; 2005.

2. Akashi M, Hasegawa T, Takahashi S, Komori T. Fourdimensional computed tomography evaluation of condylar movement in a patient with temporomandibular joint osteoarthritis. J Oral Maxillofac Surg. 2018;76(2):304-13. https://doi.org/10.1016/i.joms.2017.10.012.

3. Zarb GA, Carlsson GE. Temporomandibular disorders: osteoarthritis. J Orofac Pain. 1999;13(4):295-306.

4. Wang XD, Zhang JN, Gan YH, Zhou YH. Current understanding of pathogenesis and treatment of TMJ osteoarthritis. J Dent Res. 2015 May;94(5):666-73. https://doi.org/10.1177/0022034515574770

5. Ye T, Sun D, Mu T, Chu Y, Miao H, Zhang M et al. Differential effects of high-physiological oestrogen on the degeneration of mandibular condylar cartilage and subchondral bone. Bone. 2018 Jun;111:9-22. https://doi.org/10.1016/i.bone.2018.03.008

6. Stegenga B, Bont LG, Boering G. Osteoarthrosis as the cause of craniomandibular pain and dysfunction: a unifying concept. J Oral Maxillofac Surg. 1989;47(3):249-56. https://doi.org/10.1016/0278-2391(89)90227-9.

7. Okeson JP. Management of temporomandibular disorders and occlusion. 6th ed. Philadelphia, PA: Mosby; 2008. might be obtained in clinical findings of the TMJ OA with laser BS.

\section{Conclusion}

The biostimulation effect of the GaAlAs diode laser did not result in a significant difference in TMJ OA at histological level but may have positive effects at the clinical level. Moreover, it was observed that when appropriate BS parameters are established, significant histological improvement might be achieved. In light of the data obtained from our study, it was concluded that there is a need for new studies in order to develop different laser BS protocols for the treatment of TMJ OA.

\section{Acknowledgments}

This research is supported by theScientific Research Project Fund of Karadeniz Technical University, Trabzon, Turkey (Project Code: HDP-13482).

8. Krisjane Z, Urtane I, Krumina G, Neimane L, Ragovska I. The prevalence of TMJ osteoarthritis in asymptomatic patients with dentofacial deformities: a cone-beam CT study. Int J Oral Maxillofac Surg. 2012 Jun;41(6):690-5 https://doi.org/10.1016/i.ijom.2012.03.006

9. Axelsson S, Holmlund A, Hjerpe A. An experimental model of osteoarthrosis in the temporomandibular joint of the rabbit. Acta Odontol Scand. 1992 Oct;50(5):273-80. https://doi.org/10.3109/00016359209012773

10. Machon V, Hirjak D, Lukas J. Therapy of the osteoarthritis of the temporomandibular joint. J Craniomaxillofac Surg. 2011 Mar;39(2):127-30. https://doi.org/10.1016/j.jcms.2010.04.010

11. Melo G, Casett E, Stuginski-Barbosa J, Guerra EN, Fernandes DA, Porporatti AL et al. Effects of glucosamine supplements on painful temporomandibular joint osteoarthritis: a systematic review. J Oral Rehabil. 2018 May;45(5):414-22. https://doi.org/10.1111/joor.12616

12. Malik NA, editor. Textbook of oral and maxillofacial surgery. 3rd ed. New Delhi: Jaypee Brothers Medical; 2012.

13. Tuner J, Hode L. Laser therapy clinical practice and scientific background. Estonia: Prima Books; 2002.

14. Park JJ, Kang KL. Effect of 980-nm GaAlAs diode laser irradiation on healing of extraction sockets in streptozotocininduced diabetic rats: a pilot study. Lasers Med Sci. 2012 Jan;27(1):223-30. https://doi.org/10.1007/s10103-011-0944-8 
15. Yassaei S, Aghili H, Afshari JT, Bagherpour A, Eslami F. Effects of diode laser $(980 \mathrm{~nm}$ ) on orthodontic tooth movement and interleukin 6 levels in gingival crevicular fluid in female subjects. Lasers Med Sci. 2016 Dec;31(9):1751-9. https://doi.org/10.1007/s10103-016-2045-1

16. Magri LV, Carvalho VA, Rodrigues FC, Bataglion C, Leite-Panissi CR. Non-specific effects and clusters of women with painful TMD responders and non-responders to LLLT: double-blind randomized clinical trial. Lasers Med Sci. 2018 Feb;33(2):385-92. https://doi.org/10.1007/s10103-017-2406-4

17. Hosgor H, Bas B, Celenk C. A comparison of the outcomes of four minimally invasive treatment methods for anterior disc displacement of the temporomandibular joint. Int J Oral Maxillofac Surg. 2017 Nov;46(11):1403-10. https://doi.org/10.1016/j.ijom.2017.05.010

18. Güler N, Kürkçü M, Duygu G, Cam B. Sodium iodoacetate induced osteoarthrosis model in rabbit temporomandibular joint: CT and histological study (part I). Int J Oral Maxillofac Surg. 2011 Nov;40(11):1289-95. https://doi.org/10.1016/i.ijom.2011.07.908

19. Kerimoğlu G, Yuluğ E, Kerimoğlu S, Çıtlak A. Effects of leptin on fracture healing in rat tibia. Eklem Hastalik Cerrahisi. 2013;24(2):102-7. https://doi.org/10.5606/ehc.2013.23

20. Duygu G, Güler N, Cam B, Kürkçü M. The effects of high molecular weight hyaluronic acid (Hylan G-F 20) on experimentally induced temporomandibular joint osteoartrosis: part II. Int J Oral Maxillofac Surg. 2011 Dec;40(12):1406-13. https://doi.org/10.1016/j.ijom.2011.07.909

21. Tanaka E, Detamore MS, Mercuri LG. Degenerative disorders of the temporomandibular joint: etiology, diagnosis, and treatment. J Dent Res. 2008 Apr;87(4):296-307. https://doi.org/10.1177/154405910808700406

22. Matsumoto R, loi $H$, Goto TK, Hara A, Nakata S, Nakasima $A$ et al. Relationship between the unilateral TMJ osteoarthritis/osteoarthrosis, mandibular asymmetry and the EMG activity of the masticatory muscles: a retrospective study. J Oral Rehabil. 2010 Feb;37(2):85-92. https://doi.org/10.1111/j.1365-2842.2009.02026.x

23. Ishimaru J, Goss AN. A model for osteoarthritis of the temporomandibular joint. J Oral Maxillofac Surg. 1992;50(11):1191-5. https://doi.org/10.1016/0278-2391(92)90153-Q.

24. Guingamp C, Gegout-Pottie P, Philippe L, Terlain B, Netter P, Gillet P. Mono-iodoacetate-induced experimental osteoarthritis: a dose-response study of loss of mobility, morphology, and biochemistry. Arthritis Rheum. 1997 Sep;40(9):1670-9. https://doi.org/10.1002/art.1780400917

25. Kraan PM, Vitters EL, Beuningen HM, Berg WB. Proteoglycan synthesis and osteophyte formation in 'metabolically' and 'mechanically' induced murine degenerative joint disease: an in-vivo autoradiographic study. Int J Exp Pathol. 1992 Jun;73(3):335-50.

26. Tuner J. Medical indications: the new laser therapy handbook. Grangesberg: Prima Books; 2010.
27. Ng GY, Fung DT, Leung MC, Guo X. Ultrastructural comparison of medial collateral ligament repair after single or multiple applications of GaAlAs laser in rats. Lasers Surg Med. 2004;35(4):317-23. https://doi.org/10.1002/Ism.20077

28. Mejersjö C, Hollender L. TMJ pain and dysfunction: relation between clinical and radiographic findings in the short and long-term. Scand J Dent Res. 1984 Jun;92(3):241-8.

29. Kurita H, Kojima Y, Nakatsuka A, Koike T, Kobayashi H, Kurashina K. Relationship between temporomandibular joint (TMJ)-related pain and morphological changes of the TMJ condyle in patients with temporomandibular disorders. Dentomaxillofac Radiol. 2004 Sep;33(5):329-33. https://doi.org/10.1259/dmfr/13269559

30. Helenius LM, Hallikainen D, Helenius I, Meurman $\mathrm{JH}$, Könönen M, Leirisalo-Repo M et al. Clinical and radiographic findings of the temporomandibular joint in patients with various rheumatic diseases: a case-control study. Oral Surg Oral Med Oral Pathol Oral Radiol Endod. 2005 Apr;99(4):455-63. https://doi.org/10.1016/i.tripleo.2004.06.079

31. Mercuri LG. Osteoarthritis, osteoarthrosis, and idiopathic condylar resorption [v-vi.]. Oral Maxillofac Surg Clin North Am. 2008 May;20(2):169-83. https://doi.org/10.1016/i.coms.2007.12.007

32. Barkin S, Weinberg S. Internal derangements of the temporomandibular joint: the role of arthroscopic surgery and arthrocentesis. J Can Dent Assoc. 2000 Apr;66(4):199-203.

33. Cledes G, Felizardo R, Foucart JM, Carpentier P. Validation of a chemical osteoarthritis model in rabbit temporomandibular joint: a compliment to biomechanical models. Int J Oral Maxillofac Surg. 2006 Nov;35(11):102633. https://doi.org/10.1016/j.ijom.2006.05.003

34. Oliveira P, Sperandio E, Fernandes KR, Pastor FA, Nonaka KO, Renno AC. Comparison of the effects of low-level laser therapy and low-intensity pulsed ultrasound on the process of bone repair in the rat tibia. Rev Bras Fisioter. 2011 May-Jun;15(3):200-5. https://doi.org/10.1590/S1413-35552011000300005

35. Fangel R, Bossini PS, Renno AC, Granito RN, Wang CC, Nonaka $\mathrm{KO}$ et al. Biomechanical properties: effects of lowlevel laser therapy and Biosilicate ${ }^{\circledR}$ on tibial bone defects in osteopenic rats. J Appl Biomater Funct Mater. 2014 Dec;12(3):271-7. https://doi.org/10.5301/jabfm.5000198

36. Vescovi P, Merigo E, Manfredi M, Meleti M, Fornaini C, Bonanini $\mathrm{M}$ et al. $\mathrm{Nd}$ :YAG laser biostimulation in the treatment of bisphosphonate-associated osteonecrosis of the jaw: clinical experience in 28 cases. Photomed Laser Surg. 2008 Feb;26(1):37-46. https://doi.org/10.1089/pho.2007.2181

37. Hübler R, Blando E, Gaião L, Kreisner PE, Post LK, Xavier CB et al. Effects of low-level laser therapy on bone formed after distraction osteogenesis. Lasers Med Sci. 2010 Mar;25(2):213-9. https://doi.org/10.1007/s10103-009-0691-2 PMID:19548055 
38. Jia YL, Guo ZY. Effect of low-power He-Ne laser irradiation on rabbit articular chondrocytes in vitro. Lasers Surg Med. 2004;34(4):323-8. https://doi.org/10.1002/lsm.20017

39. Moore P, Ridgway TD, Higbee RG, Howard EW, Lucroy MD. Effect of wavelength on low-intensity laser irradiationstimulated cell proliferation in vitro. Lasers Surg Med. 2005 Jan;36(1):8-12. https://doi.org/10.1002/lsm.20117

40. Fikácková H, Dostálová T, Navrátil L, Klaschka J. Effectiveness of low-level laser therapy in temporomandibular joint disorders: a placebo-controlled study. Photomed Laser Surg. 2007 Aug;25(4):297-303. https://doi.org/10.1089/pho.2007.2053

41. Alves AC, Vieira R, Leal-Junior E, Santos S, Ligeiro AP, Albertini $R$ et al. Effect of low-level laser therapy on the expression of inflammatory mediators and on neutrophils and macrophages in acute joint inflammation. Arthritis Res Ther. 2013;15(5):R116. https://doi.org/10.1186/ar4296
42. Kamali F, Bayat M, Torkaman G, Ebrahimi E, Salavati M. The therapeutic effect of low-level laser on repair of osteochondral defects in rabbit knee. J Photochem Photobiol B. 2007 Jul;88(1):11-5. https://doi.org/10.1016/i.jphotobiol.2007.04.010

43. Muir CB, Goss AN. The radiologic morphology of asymptomatic temporomandibular joints. Oral Surg Oral Med Oral Pathol. 1990 Sep;70(3):349-54. https://doi.org/10.1016/0030-4220(90)90154-K

44. Torricelli P, Giavaresi G, Fini M, Guzzardella GA, Morrone $G$, Carpi $A$ et al. Laser biostimulation of cartilage: in vitro evaluation. Biomed Pharmacother. 2001 Mar;55(2):117-20. https://doi.org/10.1016/S0753-3322(00)00025-1

45. Godoy CHL, Motta LJ, Fernandes KPS, Mesquita-Ferrari RA, Deana AM, Bussadori SK. Effect of low-level laser therapy on adolescents with temporomandibular disorder: a blind randomized controlled pilot study. J Oral Maxillofac Surg. 2015;73(4):622-9. https://doi.org/10.1016/i.joms.2014.09.018 